\title{
Disease Flare after Discontinuation of Crizotinib in Anaplastic Lymphoma Kinase-Positive Lung Cancer
}

\author{
Yuka Kuriyama Young Hak Kim Hiroki Nagai Hiroaki Ozasa \\ Yuichi Sakamori Michiaki Mishima \\ Department of Respiratory Medicine, Graduate School of Medicine, Kyoto University, \\ Kyoto, Japan
}

\section{Key Words}

Crizotinib · Anaplastic lymphoma kinase $\cdot$ Disease flare $\cdot$ Beyond progressive disease . Non-small-cell lung cancer

\begin{abstract}
We report the case of a 50-year-old male former smoker. He was diagnosed as having lung adenocarcinoma and treated with induction chemoradiation therapy followed by surgery and adjuvant chemotherapy. Molecular testing revealed that his tumor had an echinoderm microtubule-associated protein-like 4-anaplastic lymphoma kinase (EML4-ALK) rearrangement. Therefore, he was treated with crizotinib when his disease recurred. He achieved a partial response, which persisted for 10 months until progressive disease was confirmed. Crizotinib was continued for 1 month and the tumor size increased slightly. At that time, crizotinib was discontinued and he participated in a clinical trial of erlotinib \pm Met inhibitor; however, his disease progressed rapidly after discontinuation of crizotinib, and the diagnosis of disease flare was made. Readministration of crizotinib was started immediately; however, his disease progressed rapidly, and he died 2 days after starting crizotinib retreatment. Currently, the incidence of disease flare is unknown and it is impossible to predict who will experience it. Therefore, continuing crizotinib after disease progression may be a reasonable option to avoid disease flare.


Kuriyama et al.: Disease Flare after Discontinuation of Crizotinib in Anaplastic Lymphoma Kinase-Positive Lung Cancer

\section{Introduction}

Echinoderm microtubule-associated protein-like 4-anaplastic lymphoma kinase (EML4ALK) fusion protein is an oncogenic driver for approximately 5\% of non-small-cell lung cancer (NSCLC) patients [1]. Crizotinib is an orally active ALK tyrosine kinase inhibitor which has shown marked antitumor activity in NSCLC patients who harbor EML4-ALK [2]. Among the patients who are treated with tyrosine kinase inhibitor of epidermal growth factor receptor (EGFR-TKI), some experience rapid disease progression after discontinuation of EGFR-TKI [3]. However, this phenomenon, known as disease flare, has not been well described in patients treated with ALK inhibitor. Here, we report a case of disease flare after discontinuation of crizotinib.

\section{Case Report}

A 50-year-old male former smoker was found to have a left lung nodule, $25 \mathrm{~mm}$ in size, and chest computed tomography (CT) revealed lymph node metastases in the left hilum and mediastinum. Endobronchial ultrasound transbronchial aspiration demonstrated adenocarcinoma, and he was diagnosed with lung cancer (T1bN2M0). Two cycles of cisplatin and vinorelbine chemotherapy were administered concurrently with 50 Gy thoracic irradiation. He underwent left lower lobe resection and then received 4 cycles of adjuvant chemotherapy with carboplatin and paclitaxel; however, a single pulmonary metastasis was detected in the right lower lobe, and he received 48 Gy stereotactic radiotherapy. Subsequently, he developed mediastinal lymph node metastases. Fluorescent in situ hybridization analysis revealed that his tumor had an EML4-ALK rearrangement. The administration of crizotinib $(500 \mathrm{mg} /$ day) was initiated. A partial response was achieved and maintained for 10 months (fig. 1a); however, regrowth of the mediastinal lymph nodes was confirmed (fig. 1b). Crizotinib was continued for 1 month, and the size of the lymph nodes increased slightly (fig. 1c). At that time, crizotinib was discontinued and he participated in a randomized doubleblinded phase III study of erlotinib \pm Met inhibitor. Chest CT before the start of the experimental therapy ( 2 weeks after discontinuation of crizotinib) showed evident increase of the mediastinal lymph nodes but he did not complain of any symptoms (fig. 1d). However, 1 week after the start of the experimental therapy (3 weeks after discontinuation of crizotinib), he started to complain of dyspnea and dysphagia, and chest CT revealed a marked increase of the mediastinal lymph nodes accompanying marked stenosis of the bronchus and esophagus (5 weeks after discontinuation of crizotinib) (fig. 1e). The diagnosis of disease flare was made and readministration of crizotinib was started immediately. However, his disease progressed rapidly, and he died 2 days after starting crizotinib retreatment.

\section{Discussion}

It has been recognized that some tumor cells remain sensitive to EGFR-TKI even after disease progression and that some patients experience acute exacerbation, known as disease flare, after withdrawal of EGFR-TKI [3]. However, no such phenomenon had been reported in patients treated with ALK inhibitor until recently [4]. To our knowledge, this is the second case report of disease flare in ALK-positive NSCLC.

Although there has been no clear explanation of the mechanism of disease flare, some data have indicated that the indolent nature of T790M-mediated resistance may be partly 
Kuriyama et al:: Disease Flare after Discontinuation of Crizotinib in Anaplastic Lymphoma Kinase-Positive Lung Cancer

responsible for the phenomenon in patients treated with EGFR-TKI [5]. However, the incidence of disease flare is unknown, and it is practically impossible to predict who will and will not experience disease flare after discontinuation of EGFR-TKI. This is also true for ALK inhibitor.

Although readministration is reportedly effective for disease flare after discontinuation of EGFR-TKI [6] and maybe after ALK inhibitor, rapid disease progression may deprive the patients of a second chance, as in our case. Therefore, continuing EGFR-TKI or ALK inhibitor after disease progression may be a reasonable option to avoid disease flare, and a prospective study is mandatory to verify this concept.

\section{Disclosure Statement}

No author has a financial relationship with a commercial entity that has an interest in the topic of this paper.

\section{References}

$>1$ Lindeman NI, Cagle PT, Beasley MB, Chitale DA, Dacic S, Giaccone G, Jenkins RB, Kwiatkowski DJ, Saldivar JS, Squire J, Thunnissen E, Ladanyi M: Molecular Testing Guideline for Selection of Lung Cancer Patients for EGFR and ALK Tyrosine Kinase Inhibitors: guideline from the College of American Pathologists, International Association for the Study of Lung Cancer, and Association for Molecular Pathology. J Thorac Oncol 2013;8:823-859.

-2 Camidge DR, Bang YJ, Kwak EL, Iafrate AJ, Varella-Garcia M, Fox SB, Riely GJ, Solomon B, Ou SH, Kim DW, Salgia R, Fidias P, Engelman JA, Gandhi L, Jänne PA, Costa DB, Shapiro GI, Lorusso P, Ruffner K, Stephenson $\mathrm{P}$, Tang Y, Wilner K, Clark JW, Shaw AT: Activity and safety of crizotinib in patients with ALK-positive nonsmall-cell lung cancer: updated results from a phase 1 study. Lancet Oncol 2012;13:1011-1019.

-3 Riely GJ, Kris MG, Zhao B, Akhurst T, Milton DT, Moore E, Tyson L, Pao W, Rizvi NA, Schwartz LH, Miller VA: Prospective assessment of discontinuation and reinitiation of erlotinib or gefitinib in patients with acquired resistance to erlotinib or gefitinib followed by the addition of everolimus. Clin Cancer Res 2007;13:51505155.

-4 Pop 0, Pirvu A, Toffart AC, Moro-Sibilot D: Disease flare after treatment discontinuation in a patient with EML4-ALK lung cancer and acquired resistance to crizotinib. J Thorac Oncol 2012;7:e1-e2.

-5 Oxnard GR, Arcila ME, Chmielecki J, Ladanyi M, Miller VA, Pao W: New strategies in overcoming acquired resistance to epidermal growth factor receptor tyrosine kinase inhibitors in lung cancer. Clin Cancer Res 2011;17:5530-5537.

6 Kim YH, Fukuhara A, Mishima M: Should epidermal growth factor receptor-tyrosine kinase inhibitor be continued beyond progressive disease? Case Rep Oncol 2011;4:470-474. 


\begin{tabular}{l|l}
\hline \multicolumn{2}{l}{ Case Rep Oncol 2013;6:430-433 } \\
\hline DOI: 10.1159/000354756 & $\begin{array}{l}\text { C 2013 S. Karger AG, Basel } \\
\text { www.karger.com/cro }\end{array}$ \\
\hline
\end{tabular}

Kuriyama et al.: Disease Flare after Discontinuation of Crizotinib in Anaplastic Lymphoma Kinase-Positive Lung Cancer
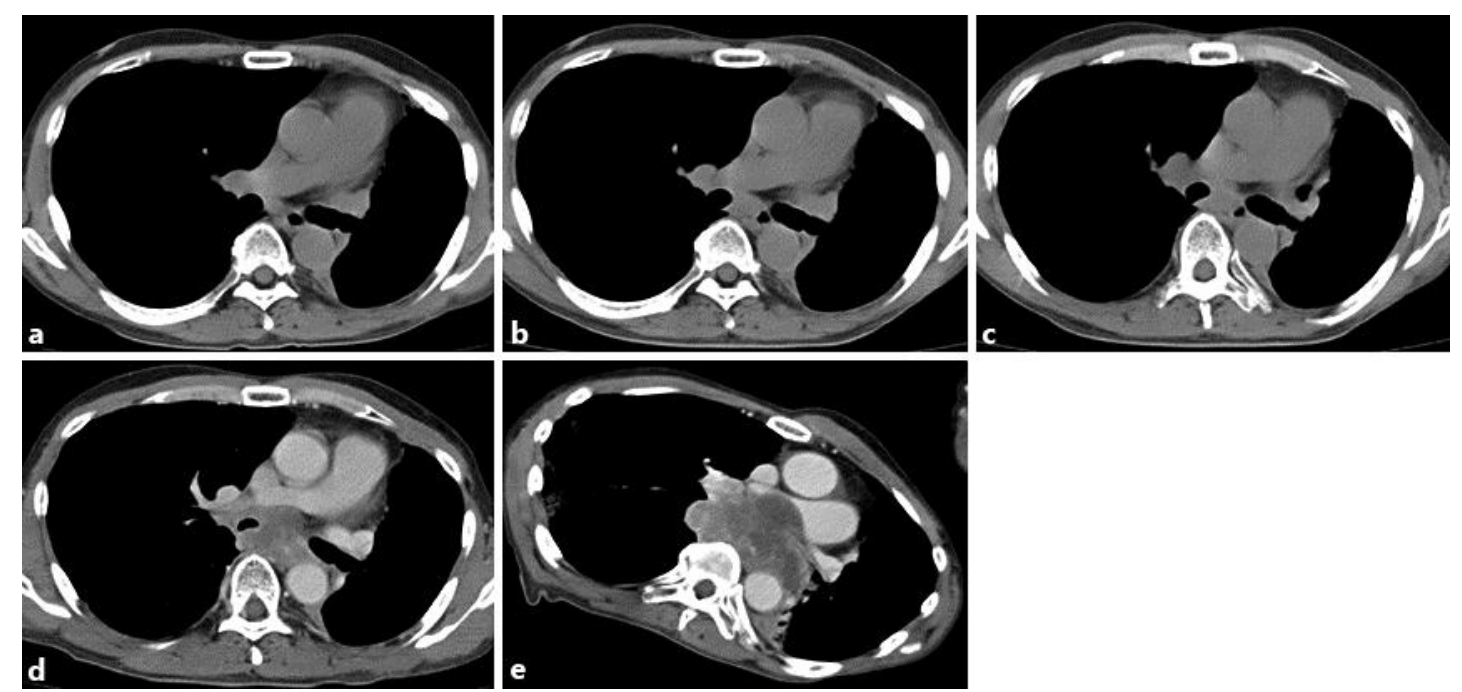

Fig. 1. Chest CT before disease progression (a), when disease progression was first confirmed (b), 1 month after disease progression (c), 2 weeks after discontinuation of crizotinib (d), and 5 weeks after discontinuation of crizotinib (e). 